\title{
Prostate cancer-specific anxiety in Dutch patients on active surveillance: validation of the memorial anxiety scale for prostate cancer
}

\author{
Roderick C. N. van den Bergh • Ida J. Korfage • \\ Gerard J. J. M. Borsboom · Ewout W. Steyerberg · \\ Marie-Louise Essink-Bot
}

Accepted: 11 July 2009/Published online: 9 August 2009

(C) The Author(s) 2009. This article is published with open access at Springerlink.com

\begin{abstract}
Purpose Men with prostate cancer (PC) may show specific disease-related anxiety. We evaluated the psychometric properties of the Dutch adaptation of the Memorial Anxiety Scale for Prostate Cancer (MAX-PC).

Methods The MAX-PC was translated using standardized forward-backward procedures. Patients $(N=150)$ on active surveillance, a strategy of initially withholding active therapy, for recently diagnosed early PC were mailed a questionnaire. Internal consistency was estimated using Cronbach's alpha. The scale structure was analyzed using confirmatory factor analysis (CFA). Construct validity was evaluated by Pearson's correlations between MAX-PC scores and scores on decisional conflict (DCS), generic anxiety (STAI), depression (CES-D), and general mental health (SF-12 MCS).

Results Data from 129 respondents were used (response rate $86 \%$ ). Cronbach's alpha for the total score and the three subscales were $0.77,0.91,0.64$, and 0.85 , respectively. CFA largely confirmed the three-factor structure as used in the original publication (model fit: $\chi^{2} 149, P=0.051$ ). The
\end{abstract}

R. C. N. van den Bergh ( $₫)$

Department of Urology, Erasmus University Medical Center,

Room NH-227, P.O. Box 2040, 3000 CA Rotterdam,

The Netherlands

e-mail: r.vandenbergh@erasmusmc.nl

R. C. N. van den Bergh · I. J. Korfage .

G. J. J. M. Borsboom - E. W. Steyerberg - M.-L. Essink-Bot

Department of Public Health, Erasmus University Medical

Center, Rotterdam, The Netherlands

M.-L. Essink-Bot

Institute of Social Medicine, Academic Medical Centre,

Amsterdam, The Netherlands patterns of directions and sizes of the correlations $(r=0.36-$ 0.66 ) between MAX-PC scale scores and the other variables were in accordance with a priori hypotheses, except for the prostate-specific antigen anxiety subscale. The relatively poor performance of this scale in the original version was replicated.

Conclusions The structure and validity of the MAX-PC to quantify PC-specific anxiety were largely confirmed in Dutch patients.

Keywords Active surveillance $\cdot$ Anxiety $\cdot$ Distress · Prostate cancer · Quality of life · Questionnaire

$\begin{array}{ll}\text { Abbreviations } \\ \text { AS } & \begin{array}{l}\text { Active surveillance } \\ \text { Confirmatory factor analysis }\end{array} \\ \text { CFA } & \begin{array}{l}\text { Centre for epidemiologic studies depression } \\ \text { scale }\end{array} \\ \text { DCS } & \begin{array}{l}\text { Decisional conflict scale } \\ \text { Memorial anxiety scale for prostate cancer }\end{array} \\ \text { MAX-PC } & \begin{array}{l}\text { Prostate cancer research international: } \\ \text { PRIAS }\end{array} \\ \text { PSA } & \begin{array}{l}\text { Prostive surveillance } \\ \text { RMSEecific antigen }\end{array} \\ \text { SF-12 MCS } & \begin{array}{l}\text { Root mean square error of approximation } \\ \text { Short-form health-survey mental component } \\ \text { summary score }\end{array} \\ \text { STAI } & \text { State trait anxiety inventory }\end{array}$

Introduction

Prostate cancer is the second largest cancer-related cause of death in men and accounts for $16 \%$ of all cancer diagnoses, 
with a rising incidence during the last years [1, 2]. Active surveillance is a relatively new treatment strategy for men with early prostate cancer. It consists of initially withholding radical treatment, but instead monitoring the disease and switching to active therapy only when progression occurs. Active surveillance may reduce overtreatment, but may cause anxiety and distress while living with 'untreated' cancer.

It is important to have an instrument that adequately measures anxiety specifically related to prostate cancer. To assess prostate cancer-specific anxiety, Roth et al. developed the Memorial Anxiety Scale for Prostate Cancer (MAX-PC) [3]. They found that the MAX-PC captured anxiety among men with prostate cancer that might be missed using other more general anxiety measures, while, for example, it is more strongly associated with changes in PSA (prostate-specific antigen) level [4].

We assessed the validity of the Dutch adaptation of the MAX-PC in Dutch men on active surveillance.

\section{Methods}

\section{MAX-PC}

The original US MAX-PC was developed for identifying and quantifying anxiety in men with prostate cancer and was designed for self-administration [3]. It consists of 18 items, divided into 3 subscales: 'prostate cancer anxiety' (11 items; example: 'Any reference to prostate cancer brought up strong feelings in me.'-Not at all, rarely, sometimes, often), 'PSA anxiety' (3 items; example: 'I have been so anxious about my PSA test that I have thought about delaying it.'-Not at all, rarely, sometimes, often), and 'fear of recurrence' (4 items; example: 'Because cancer is unpredictable, I feel I cannot plan for the future.'-Strongly agree, agree, disagree, strongly disagree). Total score ranges from 0 to 54 , with 54 indicating maximum anxiety. Scores on the 3 scales range from 0 to 33,0 to 9 , and 0 to 12 , respectively. The total MAXPC was subdivided into the three subscales as it was designed to tap three specific aspects of prostate cancerrelated anxiety, although the reliability of the 'PSA anxiety' subscale was found to be weak in the original publication [3]. To our knowledge, the MAX-PC has never been translated or used in an active surveillance setting [3-6].

\section{Translation}

The translation to Dutch followed standardized forwardbackward procedures [7]. First, three forward translations by native Dutch with a medical background with fluency in English were performed and pooled into a common version after a consensus meeting. Second, a native English speaker fluent in Dutch and also with a medical background translated this provisional Dutch version back into English, while being blinded to the original version. This back translation showed some discrepancies with the source document, but these were mainly related to the wording and not to the specific meaning of items. Consensus was reached by discussion. The Dutch version of the MAX-PC was first tested face-to-face at the respondent's home in 5 participants, who completed the questionnaire while thinking aloud in the presence of a researcher. Afterward, guided by a checklist, potential problems in acceptance or comprehension and time necessary for questionnaire completion were explored and discussed with the participant. Only minor problems, different for all 5 participants, were found during this process. These did not indicate a need to adapt the Dutch version of the MAX-PC. The Dutch version of the MAX-PC can be found at https://www.prias-project.org/modules/news/article.php? storyid $=12$.

\section{Patients}

Our study group consisted of Dutch patients who had been recently diagnosed with prostate cancer, elected active surveillance as the initial treatment option, and who consented to participate in the prospective protocol-based PRIAS (Prostate Cancer Research International: Active Surveillance) study on active surveillance [8]. If diagnosed between May 2007 and May 2008, these men received a questionnaire within 6 months after diagnosis. Men are medically eligible for the PRIAS study if they have small, localized, and well-differentiated prostate cancer. The medical ethics committee at the Erasmus University Medical Centre in Rotterdam in The Netherlands (coordinating centre) approved this study (number 2004-339).

\section{Questionnaire}

Besides the MAX-PC, the questionnaire included the Decisional Conflict Scale (DCS, 16 items with 5 response options: total score $0-100$, with 100 indicating maximum decisional conflict) to assess decisional conflict on the choice for active surveillance [9]; the Centre for Epidemiologic Studies Depression scale (CES-D, 20 items with 4 response options, total score $0-60$, with 60 indicating maximum depression) [10]; the abridged State Trait Anxiety Inventory (STAI-6, 6 items with 4 response options, total score 20-80, with 80 indicating maximum generic anxiety) [11]; and the Short Form health survey 12 (SF-12, 12 items with 2-6 response options, mean score 50, with a standard deviation of 10 in the general US population) of 
which we used the Mental Component Summary (MCS) score [12].

\section{Quality criteria}

Floor or ceiling effects causing an abnormal score distribution were considered to be present when $>15 \%$ of respondents had the lowest or the highest possible score [13].

We estimated the internal consistency by calculating the Cronbach's alpha coefficients for the total MAX-PC and the three subscales. An alpha of 0.7 is generally regarded as sufficient for group comparisons [14].

An initial confirmatory factor analysis (CFA) model was fitted in which each item was assigned to one of the three underlying factors, similar to the original publication, to verify that the original factor structure was present in our data [3]. Correlated factors were allowed in this model. The fit of the model was improved by freeing fixed parameters according to the sequence implied by the modification indices. When we found equal or nearly equal modification indices, priority was given to freeing fixed parameters in the covariance matrix of the errors over for instance fixed factor loadings [15]. Model fit was assessed with the chisquare $\left(\chi^{2}\right)$ test, the root mean square error of approximation (RMSEA), and comparative fit index (CFI).

Construct validity was assessed by comparing MAX-PC total score and the three subscale scores with DCS, CES-D, STAI-6, and SF-12 scores, respectively, using Pearson correlation coefficients. Correlations with $r>0.3$ were considered relevant [16, 17]. We hypothesized that higher scores on the total MAX-PC and subscales have to be related to higher scores on DCS, CES-D, and STAI-6, and to lower SF-12 MCS scores; that correlations were highest with STAI-6, as this measure also is anxiety specific, and lower with DCS, CES-D, and SF-12 MCS; and that correlations with the 'PSA anxiety' subscale were lower, because this is a very specific subscale, previously found to show lower construct validity. We tested differences between correlations with MAX-PC total for significance with a bootstrap procedure to obtain standard errors [18]. At least $75 \%$ of the results should be in accordance with a priori hypotheses [13].

\section{Statistical analysis}

For statistical analysis, the commercially available software Statistical Package for the Social Sciences, (version 15.0; SPSS, Inc, Chicago, IL, USA), S-Plus (version 8.0; TIBCO software, Palo Alto, CA, USA), and LISREL (version 8.72; Scientific Software International, Lincolnwood, IL, USA) [19] were used. A $P$-value of $\leq 0.05$ was considered statistically significant.

\section{Results}

Out of the 150 questionnaires sent, 129 were completed at a mean of 2.67 months (SD 1.74) after diagnosis (response rate $86 \%$ ). Patient characteristics are shown in Table 1, and questionnaire scores and distributions are shown in Table 2. All 129 men completed all 18 MAX-PC items. In 8 men, the DCS, CES-D, STAI-6, or SF-12 score were discarded, as one or more items of one of these measures were missing.

Only CES-D and the 'PSA anxiety' subscale showed floor effects, with 25 and $85 \%$ of subjects exhibiting the most favorable low score, respectively. No ceiling effects were observed.

The Cronbach's alpha coefficients for the 'prostate cancer anxiety' subscale, the 'PSA anxiety' subscale, the 'fear of recurrence' subscale, and the total MAX-PC were $0.91,0.64,0.85$, and 0.77 , respectively.

The initially fitted CFA model in which the items were assigned to the same factors as in the original publication did not fit very well $\left(\chi^{2} 271.81\right.$ with $132 d f, P<0.001$, RMSEA $=0.081$, CFI 0.95). However, the modification indices in the sequence of subsequently fitted models

Table 1 General, medical, and demographic patient characteristics $(N=129)$

\begin{tabular}{lc}
\hline General & \\
Total number of patients & 129 \\
Mean age (year) (SD) & $64.9(6.9)$ \\
Mean time (months) between questionnaire completion & $2.7(1.7)$ \\
and diagnosis (SD) & \\
Medical characteristics & \\
Mean prostate-specific antigen level (ng/ml) (SD) & $5.7(1.9)$ \\
Clinical stage & \\
T1C (\%) & $91(71)$ \\
T2 (\%) & $38(29)$ \\
Demographics & \\
Education & $86(67)$ \\
Low (primary, secondary) $(\%)$ & $42(33)$ \\
High (college, university) $(\%)$ & 1 \\
Missing & \\
Employed & $50(60)$ \\
Yes (\%) & $76(40)$ \\
No (\%) & 3 \\
Missing & \\
Hospital & $61(47)$ \\
Academic/referral centre $(\%)$ & $68(53)$ \\
Other (\%) & \\
Marital status & \\
Married/living together $(\%)$ & \\
Other (\%) & \\
\hline & \\
&
\end{tabular}


Table 2 Questionnaire scores and distributions $(N=129)$

\begin{tabular}{lrrrrlccc}
\hline & Mean & SD & Median & $\begin{array}{l}\text { 25-75 } \\
\text { Percentile }\end{array}$ & $\begin{array}{l}\text { Possible } \\
\text { score range }\end{array}$ & $\begin{array}{l}\text { Observed } \\
\text { score range }\end{array}$ & $\begin{array}{l}\text { \% Minimum } \\
\text { score }\end{array}$ & $\begin{array}{l}\text { \%aximal } \\
\text { score }\end{array}$ \\
\hline MAX-PC total & 13.9 & 8.8 & 14.0 & $(6-20)$ & $0-54$ & $0-39$ & 2 & 0 \\
$\quad$ Prostate cancer anxiety & 9.3 & 6.8 & 9.0 & $(3-14)$ & $0-33$ & $0-29$ & 5 & 0 \\
$\quad$ Prostate-specific antigen anxiety & 0.3 & 1.0 & 0.0 & $(0-0)$ & $0-9$ & $0-6$ & 85 & 0 \\
$\quad$ Fear of recurrence & 4.3 & 2.5 & 4.0 & $(2-6)$ & $0-12$ & $0-12$ & 6 & 1 \\
DCS & 27.5 & 13.7 & 28.1 & $(18.8-36.3)$ & $0-100$ & $0-67.2$ & 1 & 0 \\
CES-D & 5.7 & 6.1 & 4.0 & $(0.5-9.2)$ & $0-60$ & $0-24$ & 25 & 0 \\
STAI-6 & 35.9 & 9.0 & 35.0 & $(30-40)$ & $20-80$ & $20-66.7$ & 5 & 0 \\
SF-12 MCS & 54.1 & 8.5 & 55.6 & $(52.2-60.1)$ & Mean 50, SD 10 & $25.5-67.1$ & 0 \\
\hline
\end{tabular}

$M A X-P C$ Memorial Anxiety scale-Prostate Cancer (prostate cancer-specific anxiety)

$D C S$ Decisional Conflict Scale (decisional conflict)

$C E S-D$ Center for Epidemiologic Studies Depression scale (depression)

STAI-6 State Trait Anxiety Inventory-6 (generic anxiety)

SF-12 MCS Short-Form health-survey Mental Component Summary score (general mental health)

indicated that model fit could be substantially improved by freeing parameters in the error covariance matrix only, while leaving the factor structure unchanged. Adding 10 extra covariance parameters among a total of 153 of these parameters resulted in a just adequately fitting model $\left(\chi^{2} 148.61\right.$ with $122 d f, P=0.051$, RMSEA $=0.037$, CFI $0.99)$ that had the same factor structure as the original. These freed parameters indicated the presence of small neglected factors. Table 3 presents the factor loadings and standard deviations of the final adequately fitting CFA model.

The correlation coefficients of the MAX-PC scores with DCS, CES-D, STAI-6, and SF-12 MCS are shown in Table 4. The 'PSA anxiety' subscale did not show any relevant correlations $(r<0.3)$, while all other correlations were $>0.3$. In line with prior hypotheses, the strongest correlations of the MAX-PC and the three subscales were seen with STAI-6. The $P$-value for the difference between the correlation MAX-PC total-DCS $(r=0.41)$ and MAX-PC total-CESD $(r=0.48)$ was 0.49 , for MAX-PC total-DCS $(r=0.41)$ versus MAX-PC total-STAI-6 $(r=0.66) P$ was 0.008 . All other possible differences between correlations were significant at the 0.001 level. Correlations were in line with hypotheses in $>75 \%$.

\section{Discussion}

We largely reproduced the structure and the validity of the MAX-PC as a measure for prostate cancer-specific anxiety in a sample of Dutch prostate cancer patients on active surveillance. To our knowledge, no other questionnaires for assessing prostate cancer-specific anxiety are available.
Table 3 Factor loadings (and standard deviations) in the final adequately fitting confirmatory factor analysis model

\begin{tabular}{llll}
\hline Item & $\begin{array}{l}\text { Subscales } \\
\text { Prostate cancer } \\
\text { anxiety }\end{array}$ & $\begin{array}{l}\text { Prostate-specific } \\
\text { antigen anxiety }\end{array}$ & $\begin{array}{l}\text { Fear of } \\
\text { recurrence }\end{array}$ \\
\hline 1 & $0.59(0.07)$ & - & - \\
2 & $0.58(0.07)$ & - & - \\
3 & $0.62(0.07)$ & - & - \\
4 & $0.77(0.07)$ & - & - \\
5 & $0.64(0.07)$ & - & - \\
6 & $0.52(0.06)$ & - & - \\
7 & $0.71(0.07)$ & - & - \\
8 & $0.39(0.06)$ & - & - \\
9 & $0.38(0.06)$ & - & - \\
10 & $0.64(0.08)$ & - & - \\
11 & $0.66(0.06)$ & - & - \\
12 & - & $0.36(0.06)$ & - \\
13 & - & $0.14(0.04)$ & $0.48(0.07)$ \\
14 & - & $0.21(0.05)$ & $0.48(0.06)$ \\
15 & - & - & $0.60(0.06)$ \\
16 & - & - & $0.67(0.06)$ \\
17 & - & - & \\
18 & - & & -
\end{tabular}

The 'PSA anxiety' subscale performed relatively poor with a Cronbach's alpha of 0.64 and with no relevant correlations with other scores. These problems with the 'PSA anxiety' subscale were also observed in the original version of the MAX-PC [3, 4]. The abnormal score distribution $(85 \%$ of men in our population exhibited the lowest possible score) limits the value of the 'PSA anxiety' subscale in our study. 
Table 4 Construct validity

\begin{tabular}{|c|c|c|c|c|}
\hline $\begin{array}{l}\text { Validated outcome } \\
\text { scales }\end{array}$ & $\begin{array}{l}\text { MAX-PC I prostate } \\
\text { cancer anxiety }\end{array}$ & $\begin{array}{l}\text { MAX-PC II prostate-specific } \\
\text { antigen anxiety }\end{array}$ & $\begin{array}{l}\text { MAX-PC III fear } \\
\text { of recurrence }\end{array}$ & $\begin{array}{l}\text { MAX-PC } \\
\text { total }\end{array}$ \\
\hline DCS & $0.36 * *$ & 0.08 & $0.45 * *$ & $0.41 * *$ \\
\hline STAI-6 & $0.59 * *$ & $0.27 * *$ & $0.59 * *$ & $0.66^{* *}$ \\
\hline CES-D & $0.46 * *$ & $0.18 *$ & $0.40 * *$ & $0.48^{* *}$ \\
\hline SF-12 MCS & $-0.36 * *$ & 0.04 & $-0.38 * *$ & $-0.39 * *$ \\
\hline
\end{tabular}

Pearson correlation coefficients between scores on validated questionnaires and the three domain scores and the total score of the MAX-PC

* Correlation is significant at the 0.05 level (2-tailed)

** Correlation is significant at the 0.01 level (2-tailed)

Compared to the internal consistency scores reported in other studies (alpha of the total MAX-PC 0.89-0.90; subscales 'prostate cancer anxiety', 'PSA anxiety', and 'fear of recurrence': $0.90-0.91,0.54-0.64$, and $0.82-0.85$, respectively [3-5]), Cronbach's alpha for the total MAX-PC was somewhat lower in our cohort but similar for the subscales.

CFA largely confirmed the three-factor structure as used in the original publication. Correlation analysis provided evidence for the construct validity of the total score and the 'prostate cancer anxiety' and 'fear of recurrence' subscales but not of the 'PSA anxiety' subscale. These findings are also in line with results of the original version [3].

Our study has limitations. Future validation studies should incorporate test-retest reliability, because this is an important quality measure for questionnaires that have a discriminative purpose such as the MAX-PC and longitudinal validity. Second, our data lack any psychiatric assessment or clinical diagnosis, so cut-off points for clinical prostate cancer-specific anxiety could not be established. Finally, we evaluated only a specific subgroup of patients with prostate cancer, i.e. men who are on active surveillance and who received the diagnosis no longer than 6 months earlier. As clinimetric properties may vary between different study populations, it is recommended to further validate the MAX-PC in other prostate cancer patient cohorts, e.g. before and after surgery or radiation therapy. Only with a multiple-group model or a direct comparison with the original version of the MAX-PC, the above-mentioned assertions on the validity of the Dutch version of the MAX-PC can be confirmed.

In conclusion, we found positive evidence for the appropriateness of the MAX-PC to identify and quantify prostate cancer-specific anxiety. It may allow for comparisons between Dutch patients and other international observations and for comparisons of the effect of treatments and/or supportive measures. However, some weaknesses in the original version, especially regarding the 'PSA anxiety' subscale, were also replicated in the adapted Dutch version. The 'PSA anxiety' subscale of MAX-PC may need to be revised.
Acknowledgments The authors thank Laraine Visser-Isles for her backward-translation of the questionnaire and all 129 respondents for participation.

Open Access This article is distributed under the terms of the Creative Commons Attribution Noncommercial License which permits any noncommercial use, distribution, and reproduction in any medium, provided the original author(s) and source are credited.

\section{References}

1. Boyle, P., \& Ferlay, J. (2005). Cancer incidence and mortality in Europe, 2004. Annals of Oncology, 16(3), 481-488.

2. Jemal, A., Siegel, R., Ward, E., Hao, Y., Xu, J., Murray, T., et al. (2008). Cancer statistics, 2008. CA: A Cancer Journal for Clinicians, 58(2), 71-96.

3. Roth, A. J., Rosenfeld, B., Kornblith, A. B., Gibson, C., Scher, H. I., Curley-Smart, T., et al. (2003). The memorial anxiety scale for prostate cancer: Validation of a new scale to measure anxiety in men with prostate cancer. Cancer, 97(11), 2910-2918.

4. Roth, A., Nelson, C. J., Rosenfeld, B., Warshowski, A., O'Shea, N., Scher, H., et al. (2006). Assessing anxiety in men with prostate cancer: Further data on the reliability and validity of the memorial anxiety scale for prostate cancer (MAX-PC). Psychosomatics, 47(4), 340-347.

5. Dale, W., Hemmerich, J., \& Meltzer, D. (2007). Extending the validity of the memorial anxiety scale for prostate cancer (MAXPC) at the time of prostate biopsy in a racially-mixed population. Psychooncology, 16(5), 493-498.

6. Mehnert, A., Lehmann, C., Schulte, T., \& Koch, U. (2007). Presence of symptom distress and prostate cancer-related anxiety in patients at the beginning of cancer rehabilitation. Onkologie, 30(11), 551-556.

7. Guillemin, F., Bombardier, C., \& Beaton, D. (1993). Crosscultural adaptation of health-related quality of life measures: Literature review and proposed guidelines. Journal of Clinical Epidemiology, 46(12), 1417-1432.

8. van den Bergh, R. C., Roemeling, S., Roobol, M. J., Roobol, W., Schroder, F. H., \& Bangma, C. H. (2007). Prospective validation of active surveillance in prostate cancer: The PRIAS study. European Urology, 52(6), 1560-1563.

9. O'Connor, A. M. (1995). Validation of a decisional conflict scale. Medical Decision Making, 15(1), 25-30.

10. Roberts, R. E., \& Vernon, S. W. (1983). The center for epidemiologic studies depression scale: Its use in a community sample. American Journal of Psychiatry, 140(1), 41-46.

11. Marteau, T. M., \& Bekker, H. (1992). The development of a sixitem short-form of the state scale of the Spielberger state-trait 
anxiety inventory (STAI). British Journal of Clinical Psychology, 31(Pt 3), 301-306.

12. Ware, J., Jr., Kosinski, M., \& Keller, S. D. (1996). A 12-item short-form health survey: Construction of scales and preliminary tests of reliability and validity. Medical Care, 34(3), 220-233.

13. Terwee, C. B., Bot, S. D., de Boer, M. R., van der Windt, D. A., Knol, D. L., Dekker, J., et al. (2007). Quality criteria were proposed for measurement properties of health status questionnaires. Journal of Clinical Epidemiology, 60(1), 34-42.

14. Kathleenl, N. L. (2002). Assessing health status and quality-oflife instruments: Attributes and review criteria. Qual Life Res, 11 (3):193-205.
15. Bollen, K. A. (1989). Structural equations with latent variables. New York: Wiley Inc.

16. Fayers, P. M. (2008). The scales were highly correlated: $\mathrm{P}=0.0001$. Quality of Life Research, 17(5), 651-652.

17. Hinkle, D. E., Wiersma, W., \& Jurs, S. G. (1998). Applied statistics for the behavioral sciences (5th ed.). Boston: Houghton Mifflin College Div.

18. Efron, B., \& Tibshirani, R. J. (1993). An introduction to the bootstrap. London: Chapman \& Hall.

19. Jöreskog, K., \& Sörbom, D. (1996). LISREL 8 user's reference guide. Chicago: Scientific Software International. 